\title{
MAGNETIC PROPERTIES OF ISOTOPICALLY ENRICHED ${ }^{56} \mathrm{Fe}$
}

\author{
${ }^{1}$ Andrey BULANOV, ${ }^{2}$ Igor BELYAEV, ${ }^{1}$ Mikhail CHURBANOV, ${ }^{1}$ Yuriy BELOZEROV, \\ ${ }^{1}$ Oleg TROSHIN, ${ }^{1}$ Aleksandr POTAPOV, ${ }^{3}$ Alexander SAVCHENKO, ${ }^{3}$ Pavel MOGILNIKOV, \\ ${ }^{4}$ Sergey MELNIKOV
}

${ }^{1}$ G.G. Devyatykh Institute of Chemistry of High-Purity Substances of the Russian Academy of Sciences, Nizhny Novgorod, Russia, belozerov@ihps.nnov.ru

${ }^{2}$ A.G. and N.G. Stoletovykh Vladimir State University, Vladimir, Russia, belyaev-iv54@yandex.ru

${ }^{3}$ National Research Technological University "MISIS», Moscow, Russia

${ }^{4}$ All-Russian Scientific Research Institute of Chemical Technologies, Moscow, Russia

https://doi.org/10.37904/metal.2020.3448

\begin{abstract}
The magnetic properties of polycrystalline samples of isotopically enriched iron with the content of isotope ${ }^{56} \mathrm{Fe}$ $99.945 \pm 0.002$ at. \% were investigated. The samples of monoisotopic iron were preliminarily melted in the environment of argon and annealed in hydrogen. For the sake of comparison the same measurements were carried out on the samples of iron with natural isotopic composition. The quantity and composition of impurities in the samples of natural and monoisotopic iron were equal. The measurements were conducted by the method of vibration magnetometry with the use of the method of automatic vibro-magnetometer VSM-250 (China) using IDAW-2000D VSM test software as well as by induction-pulse method with the use of automated measuring set MK-3E (the Russia) with automatic processing of the obtained data according to GOST 8.37780 and GOST 12119.1-98. It was found that the value of saturation intensity $\mathrm{J}_{\mathrm{s}}$ in ${ }^{56} \mathrm{Fe}$ is by $4.6 \%$ higher than in natFe. There is actually no difference in saturation intensity $\mathrm{B}_{s}$ of monoisotopic ${ }^{56} \mathrm{Fe}$ and natural iron within the error in limits of detection of analysis. The difference in the values of coercitive force $\mathrm{H}_{\mathrm{c}}$, residual magnetic induction $\mathrm{Br}_{r}$ and maximum magnetic permittivity $\mu_{\max }$ in natural iron and ${ }^{56} \mathrm{Fe}$ can be explained by the difference in structure and content of impurities in the studied samples.
\end{abstract}

Keywords: Monoisotopic ${ }^{56} \mathrm{Fe}$, natural iron, phase composition, microstructure, magnetic properties

\section{INTRODUCTION}

Natural iron contains 4 stable isotopes: ${ }^{54} \mathrm{Fe},{ }^{56} \mathrm{Fe},{ }^{57} \mathrm{Fe},{ }^{58} \mathrm{Fe}$ in the ratio $5.845 ; 91.754 ; 2.119 ; 0.282$ at.\%, respectively [1,2]. The magnetic properties of natural iron are sufficiently well studied [3-5]. In contrary, the magnetic properties of separate isotopes of iron in the form of simple substance are less studied. The reliable data on this are not available. At the same time, this issue is important both for basic science and for practice. The magnetic properties that natural iron provides in technology can no longer be increased. Can individual isotopes of iron have magnetic properties higher than that of natural iron? To answer this question, it is necessary to study the magnetic properties of individual iron isotopes in comparison with the magnetic properties of natural iron. The aim of this work is to study the magnetic properties of isotopically enriched ${ }^{56} \mathrm{Fe}$.

\section{PREPARATION AND CHARACTERIZATION OF SAMPLES}

Monoisotopic iron in the powder form, obtained from iron pentacarbonyl $\mathrm{Fe}(\mathrm{CO})_{5}$, enriched with ${ }^{56} \mathrm{Fe}$ isotope by gas centrifugation, was used for the study. The isotopic composition of monoisotopic ${ }^{56} \mathrm{Fe}$ was determined by ICP-MS (mass spectrometry with ionization in inductively coupled plasma). The results of the analysis are shown in Table 1. 
Table 1 Isotopic composition of monoisotopic and natural iron, at\%

\begin{tabular}{|c|c|c|c|c|}
\hline Isotope & ${ }^{54} \mathrm{Fe}$ & ${ }^{56} \mathrm{Fe}$ & ${ }^{57} \mathrm{Fe}$ & ${ }^{58} \mathrm{Fe}$ \\
\hline${ }^{n a t} \mathrm{Fe}$ & 5.845 & 91.754 & 2.119 & 0.282 \\
\hline${ }^{56} \mathrm{Fe}$ & $0.004 \pm 0.001$ & $99.945 \pm 0.002$ & $0.040 \pm 0.001$ & $0.011 \pm 0.004$ \\
\hline
\end{tabular}

As the object of comparison, we used natural polyisotopic powder carbonyl iron produced by "Sintez-PKZh" LLC (Dzerzhinsk, Nizhny Novgorod Region) reduced in hydrogen. Further in the text of this paper the iron with natural isotopic composition will be denoted by natFe. The content of impurities in ${ }^{n a t} \mathrm{Fe}$ and ${ }^{56} \mathrm{Fe}$ was determined by laser mass spectrometry using an EMAL-2 device (USSR). The results of the analysis are shown in Table 2.

Table 2 The results of the analysis of the content of impurities in the source natFe and ${ }^{56} \mathrm{Fe}$, wt\%.

\begin{tabular}{|c|c|c|c|c|c|}
\hline \multirow{2}{*}{ Impurity } & \multicolumn{2}{|c|}{ Studied material } & \multirow{2}{*}{ Impurity } & \multicolumn{2}{c|}{ Studied material } \\
\cline { 2 - 3 } & ${ }^{n a t} \mathrm{Fe}$ & ${ }^{56} \mathrm{Fe}$ & & ${ }^{n a t} \mathrm{Fe}$ & ${ }^{56} \mathrm{Fe}$ \\
\hline $\mathrm{C}$ & $4 \cdot 10^{-2}$ & $<5 \cdot 10^{-3}$ & $\mathrm{Ca}$ & $3 \cdot 10^{-3}$ & $1 \cdot 10^{-3}$ \\
\hline $\mathrm{N}$ & $2 \cdot 10^{-3}$ & $<7 \cdot 10^{-4}$ & $\mathrm{Ti}$ & $1 \cdot 10^{-4}$ & $4 \cdot 10^{-4}$ \\
\hline $\mathrm{O}$ & 0.1 & $2 \cdot 10^{-2}$ & $\mathrm{Cr}$ & $1 \cdot 10^{-4}$ & $5 \cdot 10^{-4}$ \\
\hline $\mathrm{F}$ & $1 \cdot 10^{-3}$ & $<2 \cdot 10^{-4}$ & $\mathrm{Mn}$ & $1 \cdot 10^{-4}$ & $<2 \cdot 10^{-4}$ \\
\hline $\mathrm{Na}$ & $1 \cdot 10^{-4}$ & $2 \cdot 10^{-4}$ & $\mathrm{Co}$ & $5 \cdot 10^{-5}$ & $<5 \cdot 10^{-5}$ \\
\hline $\mathrm{Mg}$ & $1 \cdot 10^{-4}$ & $1 \cdot 10^{-4}$ & $\mathrm{Ni}$ & $2 \cdot 10^{-2}$ & $1 \cdot 10^{-4}$ \\
\hline $\mathrm{Al}$ & $2 \cdot 10^{-3}$ & $2 \cdot 10^{-3}$ & $\mathrm{Cu}$ & $6 \cdot 10^{-4}$ & 0.1 \\
\hline $\mathrm{Si}$ & $2 \cdot 10^{-4}$ & $5 \cdot 10^{-3}$ & $\mathrm{Zn}$ & $3 \cdot 10^{-3}$ & $<2 \cdot 10^{-3}$ \\
\hline $\mathrm{P}$ & $4 \cdot 10^{-3}$ & $3 \cdot 10^{-3}$ & $\mathrm{As}$ & $<2 \cdot 10^{-4}$ & $<7 \cdot 10^{-5}$ \\
\hline $\mathrm{S}$ & $2 \cdot 10^{-3}$ & $<3 \cdot 10^{-3}$ & $\mathrm{Se}$ & $2 \cdot 10^{-3}$ & $<2 \cdot 10^{-4}$ \\
\hline
\end{tabular}

From nat $\mathrm{Fe}$ and ${ }^{56} \mathrm{Fe}$ powders the tablets with diameter of $10 \mathrm{~mm}$ and thickness of $5 \mathrm{~mm}$ were pressed. All tablets had a density of $5.6 \mathrm{~g} / \mathrm{cm}^{3}$. The natFe and ${ }^{56} \mathrm{Fe}$ tablets were remelted in S-3443 vacuum electric arc furnace manufactured by the GIRedMet Experimental Plant (Russia). The furnace had a copper furnace seat and a tungsten consumable electrode. Melting was carried out in an argon atmosphere of technical purity at an overpressure of $0.1 \mathrm{~atm}$. Before melting, the getter was burned in the melting chamber in the form of titanium. The getter was burned to purify argon from impurities of oxygen, nitrogen, carbon dioxide, and water vapor. The obtained ingots had a rounded shape. Samples in the form of a parallelepiped with dimensions $1.3 \times 1.3 \times 3.5 \mathrm{~mm}$ were made from ingots by electroerosion cutting for measuring magnetic properties by vibration magnetometry. Ring samples with an outer diameter of $D=15 \mathrm{~mm}$, an inner diameter of $d=11.5 \mathrm{~mm}$ and height of $\mathrm{h}=4.0 \mathrm{~mm}$ are made to determine the magnetic properties of the induction-pulse method in quasi-static and dynamic modes. The ratio $\mathrm{D} / \mathrm{d}=1.3$ in accordance with GOST 8.377-80 and GOST 12119.1-96 when determining the magnetic characteristics of materials. The prepared samples were annealed in the flow of dry hydrogen of grade "B" (purity of $99.9999 \%$ ) at a temperature of $1100^{\circ} \mathrm{C}$ for 12 hours after which they were analyzed for impurities. The mass control of the samples before and after annealing in hydrogen was performed using Sartorius Analytic A200S electronic balance with a measurement error of $\pm 0.0001 \mathrm{mg}$. The impurity content before and after annealing in hydrogen was determined by laser mass spectrometry. After that the magnetic properties were measured in ${ }^{n a t} \mathrm{Fe}$ and ${ }^{56} \mathrm{Fe}$ samples.

\section{MEASUREMENT OF THE MAGNETIC PROPERTIES OF SAMPLES}

Before starting the measurements, the density value of the material of the measured sample was experimentally determined [6-9] as well as their phase composition. The analysis was carried out on X-ray diffractometer D8 Advance of Brucker AXS Company (Germany) in KaCu radiation. The data obtained were processed in the TOPAS program. Metallographic studies were performed using Raztec MRX9-D optical microscope (Russia). 
To measure the magnetic properties, we used the VSM-250 automated induction vibro-magnetometer (China) with data processing by IDAW-200D VSM test software and the MK-3E automated measuring complex (Russia) to perform measurements in quasi-static and dynamic modes in accordance with GOST 8.377-80 and GOST 12119.1-98. Measurements on a vibro-magnetometer were carried out at room temperature and a maximum magnetic field strength of $1538 \mathrm{kA} / \mathrm{m}(\sim 1.9 \mathrm{TL})$. Using the constructed hysteresis curves, we judged the saturation magnetization $\left(\mathrm{J}_{s}\right)$ of the measured object. When conducting studies using the MK-3E measuring complex in the quasi-static and dynamic measurement modes, the maximum magnetic field strength was 800 $\mathrm{A} / \mathrm{m}(0.001 \mathrm{TL})$. The values of coercive force $\left(H_{c}\right)$, residual magnetic induction $\left(B_{r}\right)$, saturation induction $\left(B_{s}\right)$, the maximum magnetic permeability $\left(\mu_{\max }\right)$, rectangularity coefficient of the hysteresis loop $\left(K_{s}\right)$ and magnetization reversal loss $(P)$ were determined. The relative error of measurements at confidence coefficient of 0.95 was equal to $H_{c}- \pm 2 \%, B_{r}- \pm 2 \%, B_{s}- \pm 2 \%, \mu_{\max }- \pm 5 \%$. The relative measurement error of the points of the magnetic hysteresis loop and the main magnetization curve by induction is $\pm 1.5 \%$, by magnetic field strength $\pm 2 \%$.

\section{RESULTS AND DISCUSSION}

The results of the analysis of the isotopic and impurity compositions of the initial natFe and ${ }^{56} \mathrm{Fe}$ powders are shown in Tables 1 and 2. From Table 1 it is seen that the isotopically enriched ${ }^{56} \mathrm{Fe}$ powder is almost monoisotopic. The total content of ${ }^{54} \mathrm{Fe},{ }^{57} \mathrm{Fe}$ and ${ }^{58} \mathrm{Fe}$ isotopes in it is approximately 0.055 at. \%. The impurity composition of natFe and ${ }^{56} \mathrm{Fe}$ samples prepared for measuring magnetic properties before and after their annealing in hydrogen is given in Table 3. All samples were made by the method of electroerosion cutting of ingots obtained in electric arc furnace.

Table 3 Impurity composition of ring samples of nat $\mathrm{Fe}$ and ${ }^{56} \mathrm{Fe}$ before and after their annealing in hydrogen

\begin{tabular}{|c|c|c|c|c|}
\hline \multirow{2}{*}{ Element } & \multicolumn{2}{|c|}{ Content of impurities in natFe, wt\% } & \multicolumn{2}{|c|}{ Content of impurities in ${ }^{56} \mathrm{Fe}$, wt\% } \\
\hline & Before annealing & After annealing & Before annealing & After annealing \\
\hline $\mathrm{C}$ & $\leq 5 \cdot 10^{-2}$ & $8 \cdot 10^{-3}\left(1 \cdot 10^{-2}\right)$ & $0.2(>20)$ & $1 \cdot 10^{-2}(0,7)$ \\
\hline $\mathrm{N}$ & $\leq 1 \cdot 10^{-2}$ & - & $\leq 4 \cdot 10^{-2}$ & - \\
\hline $\mathrm{O}$ & 0.3 & $0.2(2.2)$ & 2 & $0.1(3.5)$ \\
\hline $\mathrm{Na}$ & $<1 \cdot 10^{-4}$ & $<1 \cdot 10^{-4}$ & $4 \cdot 10^{-3}\left(1 \cdot 10^{-1}\right)$ & $1 \cdot 10^{-4}$ \\
\hline $\mathrm{Mg}$ & $2 \cdot 10^{-4}$ & $<4 \cdot 10^{-4}$ & $2 \cdot 10^{-4}$ & $6 \cdot 10^{-4}$ \\
\hline $\mathrm{Al}$ & - & $2 \cdot 10^{-4}$ & - & $2 \cdot 10^{-3}\left(2 \cdot 10^{-2}\right)$ \\
\hline $\mathrm{Si}$ & 0.5 & $3 \cdot 10^{-3}$ & $0.2(2)$ & $5 \cdot 10^{-2}(0.3)$ \\
\hline $\mathrm{P}$ & $4 \cdot 10^{-2}$ & $1 \cdot 10^{-2}\left(3 \cdot 10^{-2}\right)$ & $1 \cdot 10^{-3}$ & $7 \cdot 10^{-4}\left(8 \cdot 10^{-3}\right)$ \\
\hline $\mathrm{S}$ & - & $1 \cdot 10^{-3}\left(3 \cdot 10^{-2}\right)$ & - & $1 \cdot 10^{-3}\left(3 \cdot 10^{-2}\right)$ \\
\hline $\mathrm{Cl}$ & $2 \cdot 10^{-4}$ & $<3 \cdot 10^{-4}$ & $1 \cdot 10^{-3}$ & $-\quad\left(2 \cdot 10^{-2}\right)$ \\
\hline $\mathrm{K}$ & $<1 \cdot 10^{-4}$ & $<1 \cdot 10^{-3}$ & $1 \cdot 10^{-3}$ & $<1 \cdot 10^{-3}$ \\
\hline $\mathrm{Ca}$ & $3 \cdot 10^{-4}$ & $7 \cdot 10^{-3}\left(8 \cdot 10^{-2}\right)$ & $2 \cdot 10^{-3}$ & $1 \cdot 10^{-2}\left(6 \cdot 10^{-2}\right)$ \\
\hline $\mathrm{Ti}$ & $<4 \cdot 10^{-4}$ & $<2 \cdot 10^{-4}$ & $<4 \cdot 10^{-4}$ & $2 \cdot 10^{-3}$ \\
\hline $\mathrm{Cr}$ & $1 \cdot 10^{-3}$ & $<1 \cdot 10^{-3}$ & $1 \cdot 10^{-3}$ & $1 \cdot 10^{-3}\left(4 \cdot 10^{-2}\right)$ \\
\hline $\mathrm{Mn}$ & $<2 \cdot 10^{-4}$ & $<1 \cdot 10^{-3}$ & $<2 \cdot 10^{-4}$ & $<1 \cdot 10^{-3}$ \\
\hline Co & $<1 \cdot 10^{-4}$ & $8 \cdot 10^{-4}$ & $<1 \cdot 10^{-4}$ & $<5 \cdot 10^{-4}$ \\
\hline $\mathrm{Ni}$ & $5 \cdot 10^{-2}$ & $6 \cdot 10^{-2}$ & $<3 \cdot 10^{-4}$ & $3 \cdot 10^{-3}$ \\
\hline $\mathrm{Cu}$ & $5 \cdot 10^{-3}$ & $1.3(0.9)$ & $5.3(7.9)$ & $1.5(1.0)$ \\
\hline $\mathrm{Zn}$ & $5 \cdot 10^{-3}$ & $<1 \cdot 10^{-3}$ & $0.8(3.0)$ & $2 \cdot 10^{-3}$ \\
\hline
\end{tabular}

Note to Table 3: the content of impurities on the surface of the sample is indicated in parentheses. 
It can be seen from Table 3 that before annealing in hydrogen the content of carbon, nitrogen, and especially oxygen in ${ }^{56} \mathrm{Fe}$ samples was noticeably higher than in natFe samples. After annealing in hydrogen, the content of impurities in the samples decreased and leveled off. Differences in the content of impurities between natFe and ${ }^{56} \mathrm{Fe}$ persisted but became comparable. Thus, before annealing in hydrogen natFe contained less than $5 \cdot 10^{-2} \%$ of carbon and ${ }^{56} \mathrm{Fe}$ contained $0.2 \%$ of carbon. After annealing in hydrogen the content of carbon in both samples decreased: in natFe sample down to $8 \cdot 10^{-3} \%$ and in ${ }^{56} \mathrm{Fe}$ sample down to $1 \cdot 10^{-2} \%$. The content of oxygen in natFe before annealing in hydrogen was $0.3 \%$ and in ${ }^{56} \mathrm{Fe} 2 \%$, respectively. After annealing in hydrogen, the oxygen content in natFe remained virtually unchanged while in ${ }^{56} \mathrm{Fe}$ it decreased to $0.1 \%$. Before annealing in hydrogen, the silicon content in ${ }^{\text {nat }} \mathrm{Fe}$ was $0.5 \%$ and in ${ }^{56} \mathrm{Fe}$ it was $0.2 \%$. After annealing in hydrogen the content of silicon in natFe decreased down to $3 \cdot 10^{-3} \%$ and in ${ }^{56} \mathrm{Fe}$ down to $5 \cdot 10^{-2} \%$, respectively.

Phase analysis of the annealed ${ }^{n a t} \mathrm{Fe}$ and ${ }^{56} \mathrm{Fe}$ samples was carried out under identical conditions at room temperature and atmospheric pressure. The diffraction patterns are shown in Figure 1.

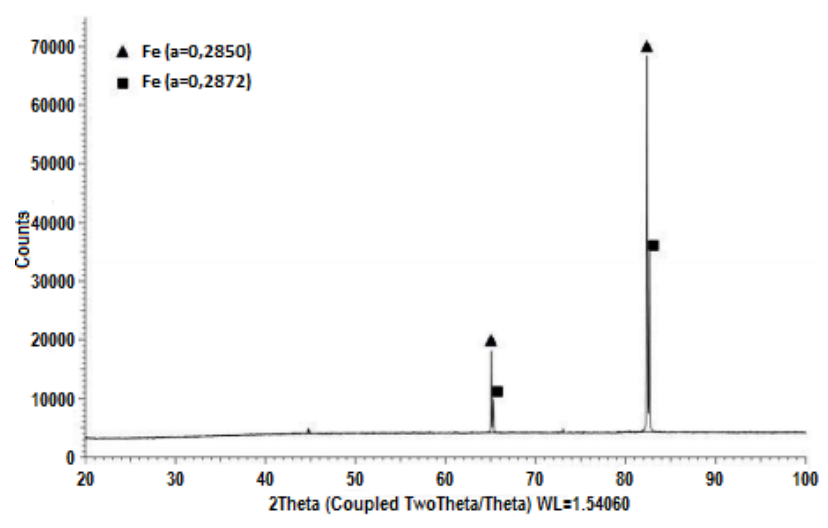

a

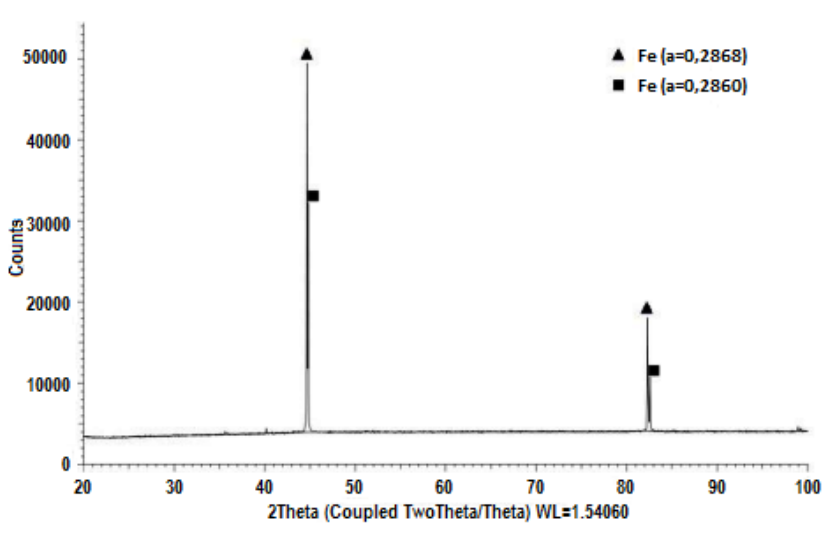

b

Figure 1 Diffraction patterns of the samples of natFe (a) and ${ }^{56} \mathrm{Fe}(\mathrm{b})$

As a result of interpretation of diffraction patterns it was found that natFe sample is completely composed of $\alpha$ Fe crystals. A part of these crystals ( $20 \%)$ has a lattice parameter $\mathrm{a}=0.2872 \mathrm{~nm}$, another part $(\sim 80 \%)$ has a parameter $\mathrm{a}=0.2850 \mathrm{~nm}$. ${ }^{56} \mathrm{Fe}$ sample actually completely consists of $\alpha$-Fe crystals with a lattice constant a $=0.2868 \mathrm{~nm}$ but contains a small amount of impurities of $\mathrm{CaO}$ and $\mathrm{Fe}_{3} \mathrm{O}_{4}$ (approximately $1 \%$ of each). It was also established that in both samples there is a crystalline texture: in the natFe sample along the crystallographic direction $\{112\}$, in the ${ }^{56} \mathrm{Fe}$ sample along the crystallographic direction $\{110\}$. Thus, the phase compositions of natFe and ${ }^{56} \mathrm{Fe}$ samples differ little from each other. Some differences exist only in the predominant crystallographic orientation of the crystals.

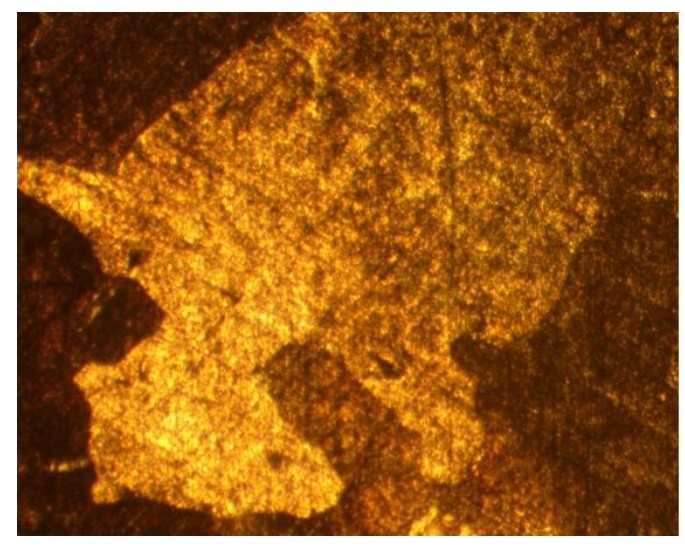

a

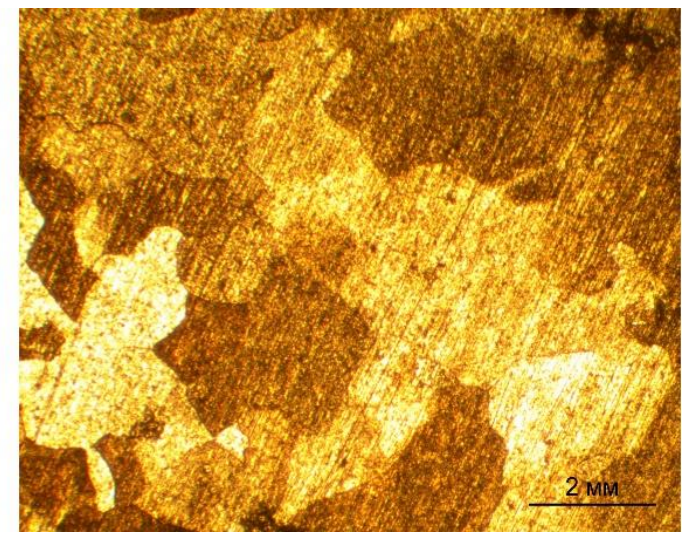

b

Figure 2 Microstructure of etched section in samples (a) natFe and (b) ${ }^{56} \mathrm{Fe}$. Optical metallography 
Metallographic studies showed that ${ }^{n a t} \mathrm{Fe}$ and ${ }^{56} \mathrm{Fe}$ samples had differences in the parameters of the macrostructure. The grain size of natFe sample is more than by 2 times exceeds the grain size of ${ }^{56} \mathrm{Fe}$ sample. Figure 2 shows the macrostructure of the etched samples of nat $\mathrm{Fe}$ and ${ }^{56} \mathrm{Fe}$.

The results of measuring the magnetic properties of samples ${ }^{n a t} \mathrm{Fe}$ and ${ }^{56} \mathrm{Fe}$ annealed in hydrogen on VSM250 magnetometer are shown in Figure 3.

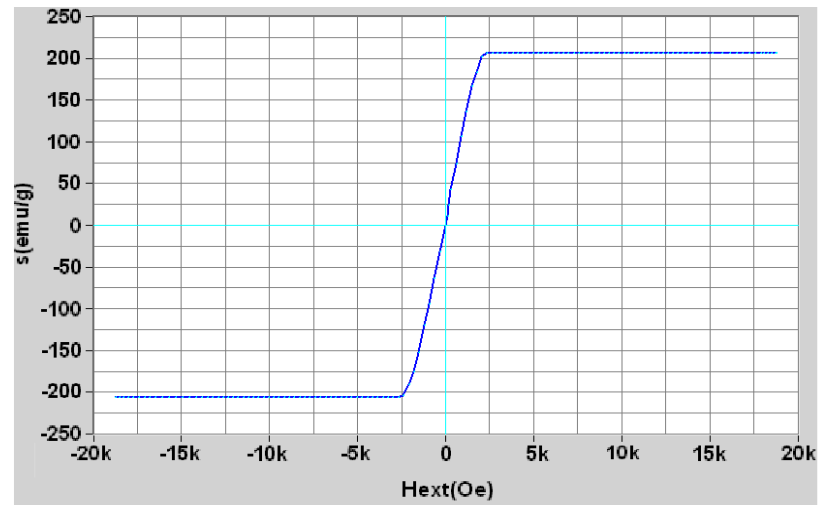

a

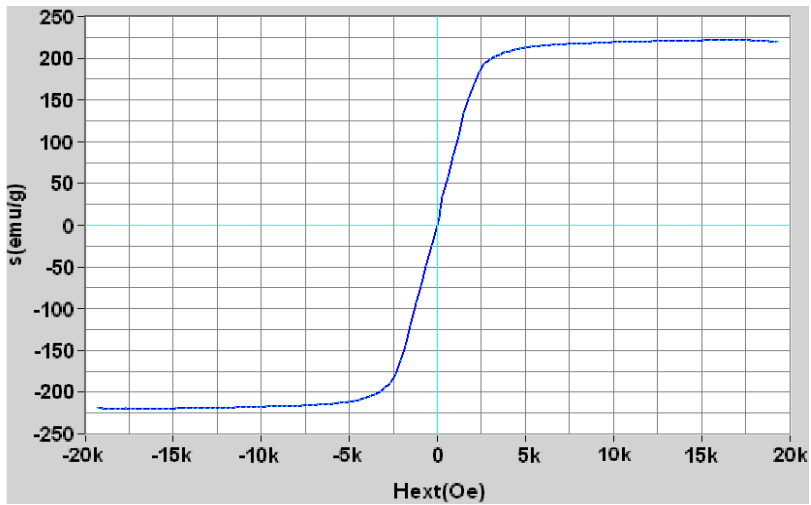

b

Figure 3 Field dependencies of specific magnetization of hydrogen annealed samples ${ }^{\text {nat }} \mathrm{Fe}(\mathrm{a})$ and ${ }^{56} \mathrm{Fe}(\mathrm{b})$ annealed in hydrogen

As it is seen from Figure 3, the saturation specific magnetization value, $\sigma_{s}$, is slightly lower in nat $F e$ than in ${ }^{56} \mathrm{Fe}$, despite the presence of isotope ${ }^{57} \mathrm{Fe}$ in natural iron which has a nuclear spin. For natFe the value $\sigma_{s}=207$ $\mathrm{A} \cdot \mathrm{m}^{3} / \mathrm{kg}$ and for ${ }^{56} \mathrm{Fe}$ the value $\sigma_{\mathrm{s}}=216.5 \mathrm{~A} \cdot \mathrm{m}^{3} / \mathrm{kg}$. Correspondingly, the saturation magnetization value, $\mathrm{J}_{\mathrm{s}}$, which is defined as $J_{s}=\sigma_{s} \cdot q$, where $q$ is the material density of the measured sample, is also lower in natFe than in ${ }^{56} \mathrm{Fe}$. The density of iron is $7.87 \mathrm{~g} / \mathrm{cm}^{3}[5]$. Then the $\mathrm{Js}_{\mathrm{s}}$ value, calculated by the above formula for ${ }^{\text {nat }} \mathrm{Fe}$, will be $1629090 \mathrm{~A} / \mathrm{m}$ or $2.05 \mathrm{~T}$ and for ${ }^{56} \mathrm{Fe}$ it is $1703855 \mathrm{~A} / \mathrm{m}$ or $2.14 \mathrm{~T}$. It is seen that the difference in values for both $\sigma_{\mathrm{s}}$ and $\mathrm{J}_{\mathrm{s}}$ in ${ }^{\text {nat }} \mathrm{Fe}$ and ${ }^{56} \mathrm{Fe}$ is $\sim 4.6 \%$. Thus, according to vibration magnetometry data, the saturation magnetization value of $\mathrm{J}_{\mathrm{s}}$ in ${ }^{56} \mathrm{Fe}$ is by $4.6 \%$ higher (more) than in ${ }^{\text {nat }} \mathrm{Fe}$.

The results of quasi-static and dynamic hysteresis magnetic properties of ring samples ${ }^{\text {nat }} \mathrm{Fe}$ and ${ }^{56} \mathrm{Fe}$ after annealing are given in Table 4.

Table 4 Results of measuring the quasi-static and dynamic hysteresis magnetic properties of ring samples ${ }^{n a t} \mathrm{Fe}$ and ${ }^{56} \mathrm{Fe}$ after their annealing in hydrogen

\begin{tabular}{|c|c|c|c|c|c|c|c|}
\hline & & \multicolumn{6}{|c|}{ Magnetic properties } \\
\hline \multicolumn{2}{|c|}{$\begin{array}{c}\text { Sample } \\
\text { material and } \\
\text { mode of } \\
\text { measurement }\end{array}$} & $\begin{array}{l}\text { Coercive } \\
\text { force, } H_{c}, \\
\text { A/m }\end{array}$ & $\begin{array}{c}\text { Rectangularity } \\
\text { coefficient of } \\
\text { hysteresis } \\
\text { loop, } K_{r}\end{array}$ & $\begin{array}{c}\text { Residual } \\
\text { magnetic } \\
\text { induction, } \\
B_{r}, T\end{array}$ & $\begin{array}{c}\text { Saturation } \\
\text { induction, } \\
B_{s,}, T\end{array}$ & $\begin{array}{c}\text { Maximum } \\
\text { magnetic } \\
\text { permeability, } \\
\mu_{\max }\end{array}$ & $\begin{array}{c}\text { Losses during } \\
\text { re- } \\
\text { magnetization, } \\
\mathbf{P}_{\text {sp }}, \mathbf{W} / \mathbf{k g}\end{array}$ \\
\hline \multirow{2}{*}{$\begin{array}{l}\frac{1}{n} \\
\frac{0}{3} \\
\frac{\pi}{0} \\
\frac{\pi}{\omega}\end{array}$} & natFe & $114.0 \pm 2.3$ & 0.88 & $0.83 \pm 0.02$ & $0.95 \pm 0.02$ & $2644 \pm 132$ & - \\
\hline & $56 \mathrm{Fe}$ & $124.5 \pm 2.5$ & 0.92 & $0.88 \pm 0.02$ & $0.95 \pm 0.02$ & $2487 \pm 124$ & - \\
\hline \multirow{2}{*}{ 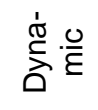 } & natFe & $2021 \pm 40$ & 0.80 & $1.28 \pm 0.03$ & $1.6 \pm 0.03$ & $2170 \pm 108$ & 83.68 \\
\hline & $56 \mathrm{Fe}$ & $1846 \pm 37$ & 0.79 & $1.28 \pm 0.03$ & $1.61 \pm 0.03$ & $1787 \pm 89$ & 76.3 \\
\hline
\end{tabular}

As can be seen from Table 4, in the quasi-static mode of measuring the magnetic properties of both samples have the same saturation induction value $B_{s}$. This indicates that the fundamental magnetic properties of natFe and ${ }^{56} \mathrm{Fe}$, independent of the sample structure, are the same. 
The increased coercive force $\left(\mathrm{H}_{\mathrm{c}}\right)$ in sample ${ }^{56} \mathrm{Fe}$, compared to natFe, can be explained by the differences in grain sizes of these samples. Sample ${ }^{56} \mathrm{Fe}$ has a smaller grain size and, therefore, has a larger coercive force. This relationship between grain size and coercive force is well known in physical metallurgical science $[3,4,10]$.

The increased value of the residual induction of $\mathrm{B}_{r}$ in sample ${ }^{56} \mathrm{Fe}$ compared to nat $\mathrm{Fe}$ appears to be due to the presence of a more pronounced crystalline texture in sample ${ }^{56} \mathrm{Fe}$. This is evidenced by a higher value of the rectangularity coefficient of hysteresis loop $\mathrm{K}_{\mathrm{r}}$ in sample ${ }^{56} \mathrm{Fe}$ as compared to sample nat $\mathrm{Fe}$.

The higher $\mu_{\max }$ value in ${ }^{\text {nat }} \mathrm{Fe}$, compared to ${ }^{56} \mathrm{Fe}$, is probably due to the larger grain size and lower impurities content in this sample (in ${ }^{\text {nat }} \mathrm{Fe}$ ), primarily of carbon.

During measurement of magnetic properties in the dynamic mode at frequency $50 \mathrm{~Hz}$ the values of induction of saturation $B_{s}$ and residual magnetic induction $B_{r}$ as well as the values of rectangularity coefficients of loops of hysteresis $\mathrm{K}_{r}$ in investigated samples are actually equal. The values of the coercive force $\mathrm{H}_{c}$, maximum magnetic permeability $\mu_{\max }$, and specific losses during re-magnetization of $\mathrm{P}_{\mathrm{sp}}$ are higher in ${ }^{\text {nat }} \mathrm{Fe}$ than in ${ }^{56} \mathrm{Fe}$ : $\mathrm{H}_{\mathrm{c}}$ by $9.5 \% ; \mu_{\max }$ by $21 \%$; $\mathrm{P}_{\mathrm{sp}}$ by $9.7 \%$.

Table 4 shows that in the quasi-static method of measuring magnetic properties, the coercive force $\mathrm{H}_{\mathrm{c}}$ in ${ }^{56} \mathrm{Fe}$ is by $\sim 9.2 \%$ higher than in natFe. In the dynamic measurement method, on the contrary, $\mathrm{H}_{\mathrm{c}}$ in ${ }^{56} \mathrm{Fe}$ is by $\sim 9.5$ $\%$ less than in ${ }^{\text {nat }} \mathrm{Fe}$ sample, respectively. This seems to be due to the fact that in the quasi-static measurement method, when the increase in magnetization field strength occurs relatively slowly, the grain size of the measured sample is of greater importance in the process of magnetization and re-magnetization. In the dynamic measurement method, when the direction of magnetization field changes rapidly (at $50 \mathrm{~Hz}$ ), impurities (primarily oxygen) have a greater effect on the magnetization process. These impurities and their compounds complicate the processes of re-magnetization of the material of the sample reversal of magnetization domains with rapid change in the direction of magnetic field. The same seems to explain the higher value of $P_{\text {sp }}$ (specific losses during magnetization) in natFe sample as compared to ${ }^{56} \mathrm{Fe}[10]$.

\section{CONCLUSION}

The measured fundamental magnetic properties of natural ( $\left.{ }^{\text {nat }} \mathrm{Fe}\right)$ and monoisotopic $\left({ }^{56} \mathrm{Fe}\right)$ iron are almost the same. The excess of saturation magnetization in ${ }^{56} \mathrm{Fe}$ compared to natFe is $4.6 \%$. Small differences in saturation induction values, $B_{s}$, are within the limits of the measurement error and are not significant values.

Differences in the values of coercive force $\left(H_{c}\right)$, residual magnetic induction $\left(B_{r}\right)$, maximum magnetic permeability $\left(\mu_{\max }\right)$ as well as the rectangularity coefficient of hysteresis loop $\left(\mathrm{K}_{\mathrm{r}}\right)$ in samples ${ }^{\text {nat }} \mathrm{Fe}$ and ${ }^{56} \mathrm{Fe}$ are due to differences in the purity of these samples with respect to impurities and differences in their crystalline structure. The absence of a noticeable contribution to the saturation magnetization of natural iron samples from isotope ${ }^{57} \mathrm{Fe}$, which has a nuclear spin, may be associated with a small magnetic moment of the latter in comparison with the magnetic moments of the electron shells of iron atoms.

Replacing ${ }^{\text {nat } F e ~ f o r ~}{ }^{56} \mathrm{Fe}$ is unlikely to result in a significant change in the physical, technical and functional properties of iron and its alloys. This question, however, requires experimental confirmation while measuring the samples with higher chemical purity.

\section{REFERENCES}

[1] BARANOV, V. YU. Izotopy: svoystva, poluchenie, primenenie. FIZMATLIT, 2005, t.1, p.600 and t.2, p. 728.

[2] GREENWOOD, N., EARNSHAW, A. Khimiya elementov (in 2 volumes). BINOM, Laboratoriya znanii, 2008.

[3] HECK, C. Magnitnye materialy $i$ ih primenenie. Energiya, 1973, p. 304.

[4] PROBRAZHENSKI, A.A., BISHARD E.G. Magnitnye materialy i elementy. Vysshaya shkola, 1986, p. 352.

[5] KIKOIN, I. K. Tablitsy fizicheskih velichin. Spravochnik. Atomizdat, 1976, p. 1008. 
[6] GOST 8.377-80. Materialy magnitomyagkie. Metodika Metodika vypolneniya izmereniy pri opredelenii statisticheskikh magnitnykh kharakteristik. Izdatelstvo standartov, 1980, p. 22.

[7] GOST 12119.1-98. Stal' elektrotekhnicheskaya. Metody opredeleniya magnitnykh i elektricheskikh svoystv. Izdatelstvo standartov, 1972, p. 38.

[8] PRUDNIKOV, V.N. Eksperimental'nye metody v magnetizme. Lektsii. Chast‘ 1. Fizicheskii fakultet MGU, 2009, pp. 84-101.

[9] PEROV, N.S., RODIONOVA, V.V., PRUDNIKOV, M.V., GRANOVSKII, A.B., PRUDNIKOV, V.N. Vibratsionnyi magnetometer. Spetsialnyi fizicheskiy praktikum. M.V. Lomonosov Fizicheskii fakultet MGU, 2016, p. 44.

[10] KEKALO, I.B. SAMARIN, B.A. Fizicheskoye metallovedenie pretsizionnykh splavov. Splavy s osobymi magnitnymi svoystvami. Metallurgiya, 1989, p. 496. 